Article

\title{
Nanoindentation of $\gamma$-TiAl with Different Crystal Surfaces by Molecular Dynamics Simulations
}

\author{
Xiaocui Fan ${ }^{1}$, Zhiyuan Rui ${ }^{1,2, *}$, Hui Cao ${ }^{1}$, Rong Fu ${ }^{1}$, Ruicheng Feng ${ }^{1,2}$ and Changfeng Yan ${ }^{1,2}$ \\ 1 School of Mechanical and Electronical Engineering, Lanzhou University of Technology, \\ Lanzhou 730050, China; xiaoc_fan@163.com (X.F.); c_hui0722@126.com (H.C.); f_rong0901@126.com (R.F.); \\ frcly@163.com (R.F.); changf_yan@163.com (C.Y.) \\ 2 State Key Laboratory of Advanced Processing and Recycling of Non-ferrous Metals, Lanzhou University of \\ Technology, Lanzhou 730050, China \\ * Correspondence: zhiy_rui@163.com; Tel.: +86-0931-2758258
}

Received: 14 January 2019; Accepted: 1 March 2019; Published: 6 March 2019

check for updates

\begin{abstract}
The periodicity and density of atomic arrangement vary with the crystal orientation, which results in different deformation mechanisms and mechanical properties of $\gamma$-TiAl. In this paper, the anisotropic characteristics for $\gamma$-TiAl with (100), (110) and (111) surfaces during nanoindentation at $300 \mathrm{~K}$ have been investigated by molecular dynamics simulations. It is found that there is no obvious pop-in event in all load-depth curves when the initial plastic deformation of $\gamma$-TiAl samples occurs, because the dislocation nucleates before the first load-drop; while a peak appears in both the unloading curves of the (110) and (111) samples due to the release of energy. Stacking faults, twin boundaries and vacancies are formed in all samples; however, interstitials are formed in the (100) sample, a stacking fault tetrahedron is formed in the (111) sample; and two prismatic dislocation loops with different activities are formed in the (110) and (111) samples, respectively. It is also concluded that the values of the critical load, strain energy, hardness and elastic modulus for the (111) sample are the maximum, and for the (100) sample are the minimum. Furthermore, the orientation dependence of the elastic modulus is greater than the hardness and critical load.
\end{abstract}

Keywords: nanoindentation; $\gamma$-TiAl; crystal orientation; molecular dynamics simulation

\section{Introduction}

Currently, micro-electromechanical systems (MEMS) have been successfully applied in fields such as biology or aerospace, which means that components of MEMS should be suitable for an increasingly complex working environment. As an intermetallic compound material, $\gamma$-TiAl has the high temperature strength and specific modulus, excellent oxidation resistance and flame retardance, low density and expansion coefficient, these advantages give it great application potential in the field of MEMS [1-4].

Since the MEMS devices can be manufactured at the nanoscale, the mechanical properties of nanomaterials show great significance for their application. Nanoindentation is an effective method to measure the mechanical properties of materials at the nanoscale, such as the elastic modulus, hardness and strain hardening effect. So far, this technology has been applied to obtain the mechanical properties of various materials including not only pure metals such as $\mathrm{Al}, \mathrm{Cu}, \mathrm{Ag}, \mathrm{Ni}$, and $\mathrm{Fe}$ [5-8]; but also alloys such as $\mathrm{TiAl}, \mathrm{U}-\mathrm{Cu}, \mathrm{Fe}-\mathrm{Ni}-\mathrm{C}, \mathrm{Zr}-\mathrm{Cu}-\mathrm{Ag}-\mathrm{Al}$ and nickel superalloys [9-15].

However, it is difficult to investigate the transient atomic information inside the materials during nanoindentation experiments $[16,17]$. As a powerful supplement to the experiments, the molecular dynamics method can simulate the atomic-scale interaction between the indenter and materials, analyze the defect evolution, and then obtain the mechanical properties and deformation mechanism 
in detail [18]. Liu and Jiao et al. [19,20] studied the formation mechanism of prismatic dislocation loop and stacking fault tetrahedron during the nanoindentation of $\mathrm{Al}$ and $\mathrm{Cu}$, respectively. Shih-Wei and Talaei et al. [21,22] investigated the grain boundary effects on the indentation-induced plastic deformation of $\mathrm{Cu}$ and Fe. Abu-Shams and Biao et al. [23,24] revealed the effect of void on the nanoindentation of $\mathrm{Fe}-10 \% \mathrm{Cr}$ and Ni alloy. Furthermore, Dasilva et al. [25] found that both emission and interaction of dislocations in $\gamma$-TiAl were mediated by the expansion of glide loops on the $\{111\}$ planes resulting in the formation of prismatic loops. Xu et al. [26] observed that the critical load increased with the indentation depth, while the indentation speeds of $0.001-0.15 \AA / p s$ had little influence on Young's modulus of $\gamma$-TiAl.

In general, the periodicity and density of atomic arrangement vary with the crystal orientation, which results in different physical properties of crystals. Jun et al. [27] performed nanoindentation tests on dual-phase Ti alloys and found that the grain orientation had a significant influence on the local strain rate sensitivity of Ti6242. Ziegenhain et al. [28] carried out the nanoindentation simulations of $\mathrm{Cu}$ and $\mathrm{Al}$, the result showed that the influence of the surface orientation was lost when the plastic deformation had set in. Xiong et al. $[29,30]$ found that the critical load, dislocation nucleation position and critical contact pressure were associated with the crystal orientation of $\mathrm{Ni}_{3} \mathrm{Al}$ and $\mathrm{FeNi}_{3}$. Kempf et al. [31] indicated that the different gamma domains had little influence on the hardness of twinned TiAl with (110) and (111) gamma by nanoindentation experiment, while the plastic anisotropy caused significant differences in the pile-up. Zambaldi et al. [32] studied the plastic anisotropy of $\gamma$-TiAl and confirmed that the easy activation of ordinary dislocation glided in stoichiometric $\gamma$-TiAl. In addition, the lattice instability of $\gamma$-TiAl at $0.1 \mathrm{~K}$ was investigated by nanoindentation simulation, it was found that the orientation of crystal affected the stress field and the nucleation of dislocation [16].

Although there are several works about $\gamma$-TiAl with different surfaces, the effect of crystal orientation on the deformation mechanisms and mechanical properties of $\gamma$-TiAl at room temperature is still not sufficiently clear. In order to supply the current inadequacy, in this paper, LAMMPS [33] is used to simulate the nanoindentation processes (loading and unloading) of $\gamma$-TiAl with (100), (110) and (111) surfaces at $300 \mathrm{~K}$. The defect evolution, load-depth curve, hardness, elastic modulus, critical load and strain energy for different samples are analyzed in detail.

\section{Materials and Methods}

For each case in the present study, as illustrated in Figure 1, the nanoindentation model consists of the indenter and substrate. The indenter is a diamond sphere with a radius of $28 \AA$, which is regarded as a rigid body, and its tip is positioned $7.4 \AA$ apart from the crystal surface at first. The size of $\gamma$-TiAl substrate is $220 \AA \times 220 \AA \times 220 \AA$, including the boundary layer, thermostat layer and Newtonian layer. The thickness of the boundary layer is $10 \AA$, atoms in this region are fixed to prevent the substrate from moving. The thermostat layer using the velocity rescaling method helps to control the temperature of the whole system, its thickness is $30 \AA$. The thickness of the Newtonian layer is $180 \AA$, atoms in this region obey Newton's law of motion. The interaction of Al-Ti is described by the embedded atom method (EAM) potential [34]. The interaction of C-C is neglected because the indenter is rigid. The interactions of $\mathrm{C}-\mathrm{Al}$ and $\mathrm{C}-\mathrm{Ti}$ are described by the Mie 6-12 potential (often called the Lennard-Jones potential) [35]:

$$
U(r)=4 \epsilon\left[\left(\frac{\sigma}{r}\right)^{12}-\left(\frac{\sigma}{r}\right)^{6}\right], r<r_{0}
$$

where $\epsilon$ is the depth of potential well, $\sigma$ is the equilibrium distance, and $r_{0}$ is the cutoff distance. These parameters are listed in Table 1 [27,36], and the cutoff distance is 2.5 times the equilibrium distance [37]. 


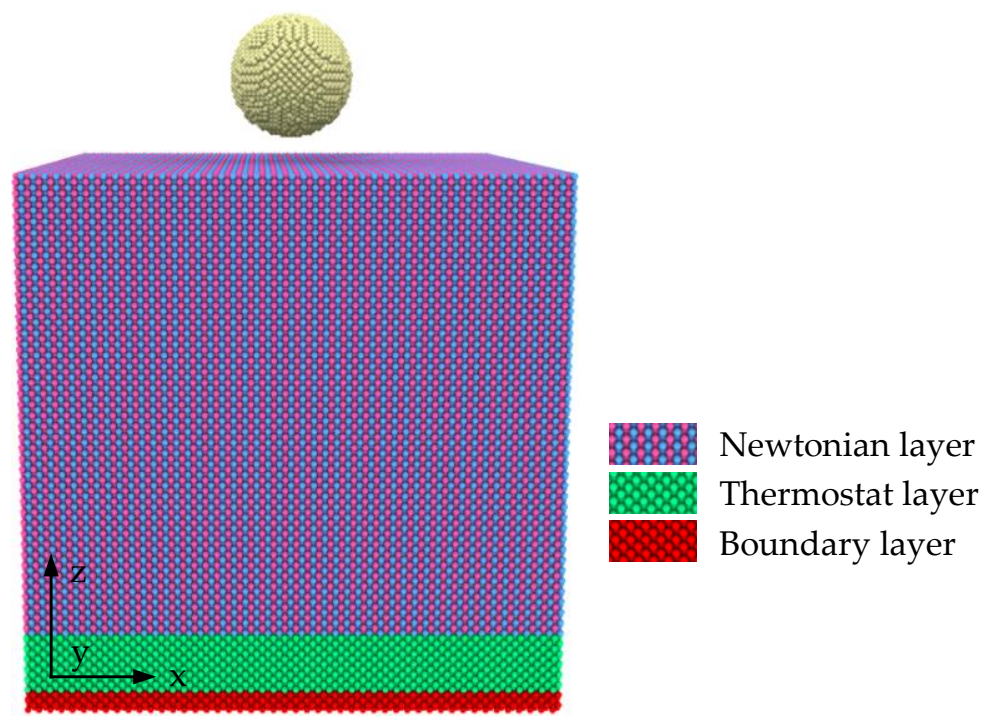

Figure 1. Nanoindentation model of $\gamma$-TiAl.

Table 1. Mie 6-12 (Lennard-Jones) potential function parameters used in simulation.

\begin{tabular}{cccc}
\hline Parameters & $\sigma(\AA)$ & $\boldsymbol{\epsilon}\left(\mathbf{1 0}^{-\mathbf{1}} \mathbf{e v}\right)$ & $\boldsymbol{r}_{\mathbf{0}}(\mathbf{\mathrm { A }})$ \\
\hline $\mathrm{C}-\mathrm{Al}$ & 2.976 & 3.15 & 7.44 \\
$\mathrm{C}-\mathrm{Ti}$ & 3.759 & 0.314 & 9.398 \\
\hline
\end{tabular}

Owing to the limitation of computing power, the loading speed in molecular dynamics simulations is generally in the range of $1-100 \mathrm{~m} / \mathrm{s}$ [38], although which is much higher than the $10^{-6}-10^{-9} \mathrm{~m} / \mathrm{s}$ in nanoindentation experiments $[39,40]$. In this paper, a speed of $50 \mathrm{~m} / \mathrm{s}$ is applied along the direction of $-z$, and that was also chosen in other studies [41,42]. The time step used is $1 \mathrm{fs}$, and the maximal indentation depth is $22.6 \AA$. The free boundary condition is applied along the $\mathrm{z}$-direction, and periodic boundary conditions are applied along the $\mathrm{x}$ and $\mathrm{y}$ directions to eliminate the effect of boundary conditions on the side faces. Besides, the initial relaxation was performed properly for 380 ps at $300 \mathrm{~K}$ before indentation to make the system to be in equilibrium.

The crystal structures of different $\gamma$-TiAl samples are displayed in Figure 2 , the base vectors $\mathrm{x}, \mathrm{y}$

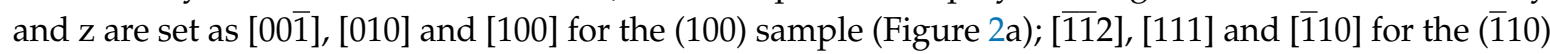
sample (Figure 2b); and [112], [1]̄0] and [111] for the (111) sample (Figure 2c).
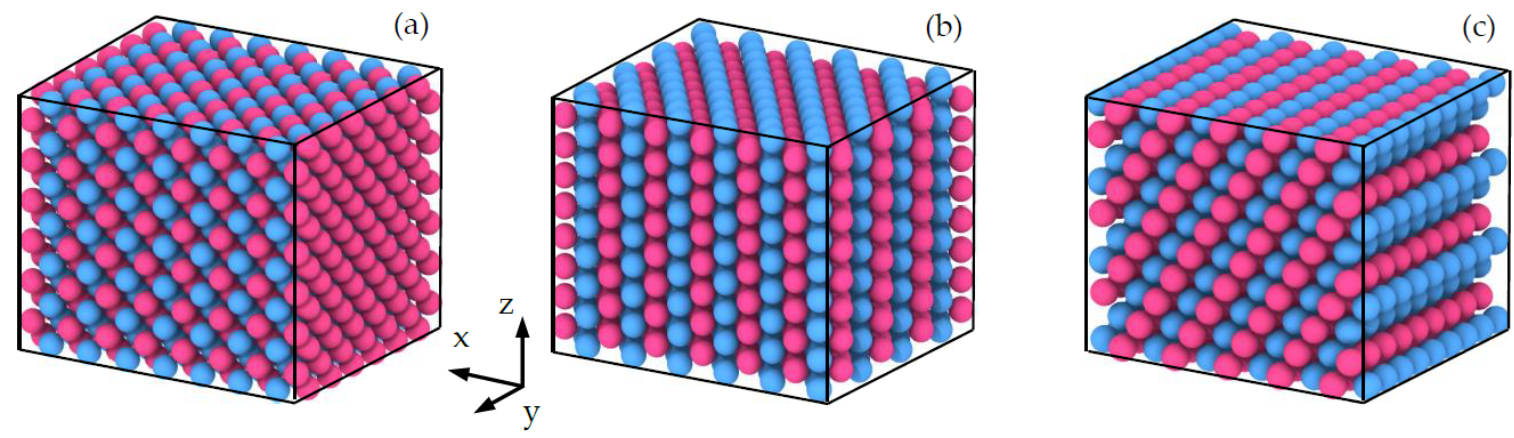

Figure 2. The crystal structure of (a) the (100) sample, (b) the (110) sample and (c) the (111) sample. The $\mathrm{Ti}$ atoms are colored purple and the $\mathrm{Al}$ atoms are colored blue. 


\section{Results}

\subsection{Analysis of Load-Depth Curves}

The load-depth curves with characteristic marks are depicted in Figure 3. The repulsive force is positive and the attractive force is negative. The summation of the vertical components of the force exerted on the indenter by the substrate is considered as the load. The force can be obtained by the derivative of the Mie 6-12 (Lennard-Jones) potential function.
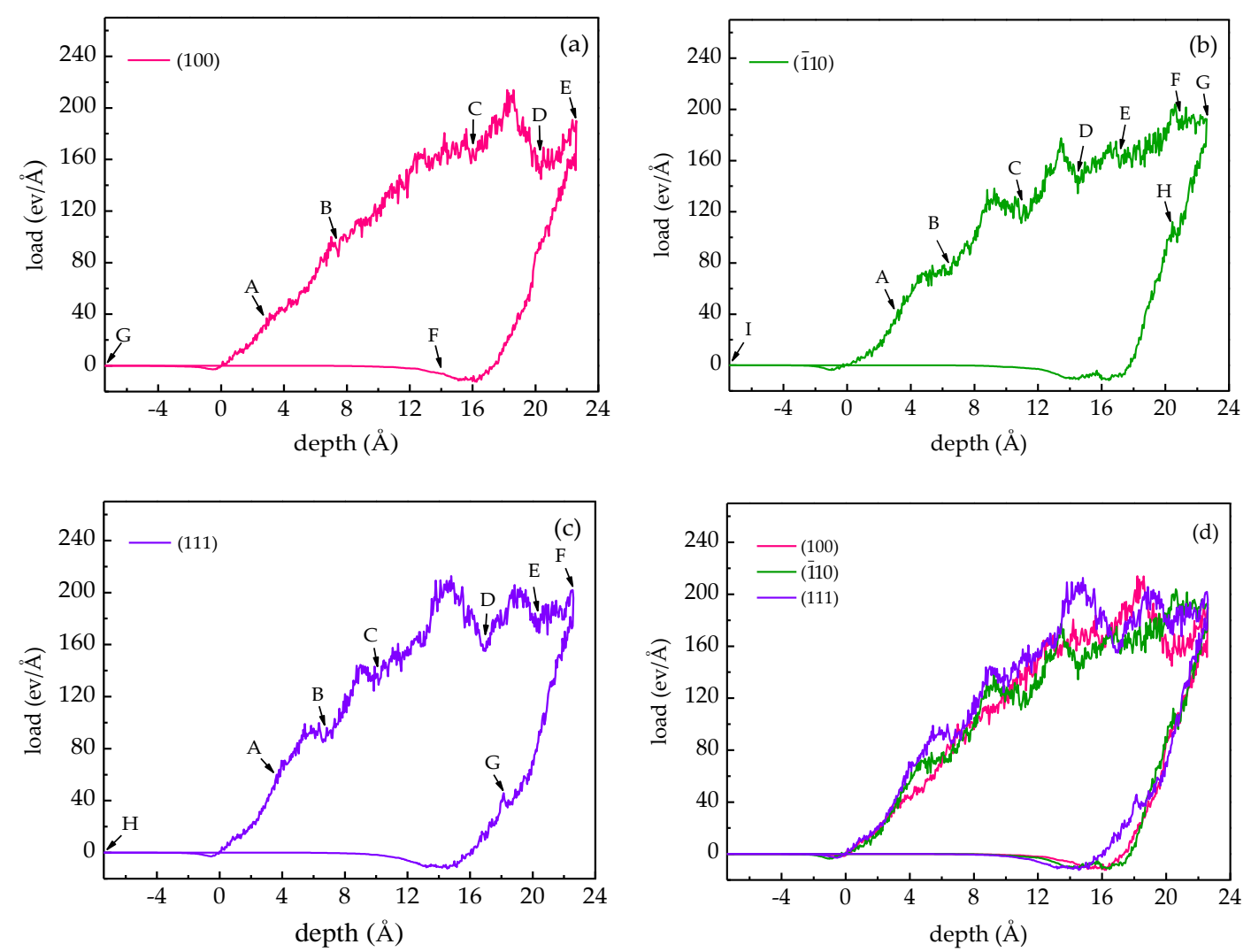

Figure 3. Load-depth curve of (a) the (100) sample, (b) the (110) sample and the (c) (111) sample; (d) shows the load-depth curves of the three different samples. The letters labeled in (a-c) represent the characteristic points, and the defect evolution at these points will be described in Section 3.2.

For each case, the whole nanoindentation procedure can be divided into four stages as follows: stage I, the indenter is approaching the substrate. When the indenter is positioned about $2 \AA$ apart from the substrate, there is an attraction between the indenter and the substrate surface. However, the attraction is too small to make the atoms of the substrate surface leave their original positions and adhere to the indenter. Stage II, the indenter is pressing into the substrate. A repulsive force exists between the indenter and substrate and increases with the indentation depth. Stage III, the indenter is returning and the load is positive. The indenter begins to return after reaching the maximum depth, and the load decreases as the indenter returns. Due to the plastic deformation occurring in the $\gamma$-TiAl substrate when the load decreases to zero, the indenter cannot return to its original position. Stage $\mathrm{IV}$, the indenter continues to move back while the load is not positive. In the meantime, there is only an attraction between the indenter and $\gamma$-TiAl substrate before the load is zero, and then the indenter returns to its original position gradually.

During each loading process, several pop-in events are observed in the load-depth curve, which can be attributed to the release of strain energy accumulated during the deformation through dislocation activities. It is generally believed that the first pop-in event represents the occurrence of 
initial plastic deformation [43]. However, because the dislocation nucleates prior to the first load drop, there is no pronounced pop-in event in the load-depth curve when the initial plastic deformation occurs in this study; in the nanoindentations of $\mathrm{Ni}_{3} \mathrm{Al}$ and $\mathrm{Co}$, similar behaviors were observed $[29,44]$.

During the unloading process, peaks H and G appear in the load-depth curves of the (110) and (111) samples, respectively. This is associated with the dislocation annihilation that will cause the release of energy.

The critical load of the transformation of elastic-plastic deformation is the force exerted by the indenter on the sample when the initial dislocation nucleates. The critical depth of the initial dislocation nucleation can be obtained by the Ovito, and the critical load can be obtained by the critical depth from the load-depth curves in Figure 3. Note that the critical load is $36.71 \mathrm{ev} / \AA$ of the (100) sample, $41.38 \mathrm{ev} / \AA$ of the (110) sample and $53.29 \mathrm{ev} / \AA$ of the (111) sample. Obviously, the value of the (100) sample is the minimum, and that of the (111) sample is the maximum. The results are consistent with the previous study [16]. It indicates that the resistance to plastic deformation of (111) sample is the strongest, while that of the (100) sample is the weakest.

\subsection{Analysis of Defect Evolution}

In this work, the centrosymmetry parameter (CSP) [45] and dislocation extraction algorithm (DXA) [36] are used to visualize and identify interior defects in samples during nanoindentation. Figures 4-6 present a series of snapshots exhibiting the defect evolution in different $\gamma$-TiAl samples, corresponding to the characteristic points marked in the load-depth curves of Figure 3. The Other atoms are coloured white, the HCP atoms are coloured pink and the FCC atoms are coloured green. The Stair-rod dislocation lines are coloured purple, the Hirth dislocation lines are coloured yellow, the Perfect dislocation lines are coloured blue and the Shockley dislocation lines are coloured green. Besides, a single HCP atom layer represents a twin boundary, two adjacent HCP atom layers present an intrinsic stacking fault, and an FCC atom layer in the middle of two HCP atom layers stands for an intrinsic stacking fault.

Initially, $\gamma$-TiAl deforms elastically without defect nucleation. With the increasing indentation depth, the substrate atoms beneath the indenter deviate from their original positions and arrange disorderly, the strain energy increases, and then the dislocation nucleates causing plastic deformation. Because the dislocation sources exist in $\gamma$-TiAl, the number of dislocations increases with the indentation depth. The dislocation multiplication is dominated by the Shockley dislocation, which can improve the slip ability of the sample that intensifies the plastic deformation.

\subsubsection{Analysis of Defect Evolution for the (100) Sample}

In Figure $4 a$, when the indentation depth is $3.2 \AA$ (corresponding to A in Figure 3a), a dislocation embryo nucleates below the top surface, then the sample enters the plastic deformation stage. Subsequently, the atoms around the dislocation embryo gradually deviate from their equilibrium positions and develop into a dislocation. Dislocations glide with the increasing indentation depth, which may destroy the normal periodic arrangement of atoms and results in the formation of stacking faults (SFs). As shown in Figure $4 \mathrm{~b}$, as the depth increases to $7.45 \AA$ (corresponding to B in Figure 3a), an intrinsic stacking fault (SISF) on the (1111) plane is formed; moreover, a $1 / 2[0 \overline{11}]$ superpartial dislocation dissociates into $1 / 6[1 \overline{21}]$ and $1 / 6[\overline{112}]$ Shockley dislocations connected by an SISF on

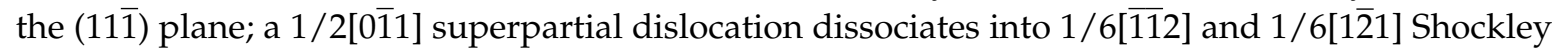
dislocations connected by an SISF on the (111) plane. The dislocation dissociations occur due to the low enough SF energies [46].

With the further increasing indentation depth, the stacking faults grow because of various dislocation activities. In Figure 4c, as the depth reaches $15.9 \AA$ (corresponding to C in Figure 3a), the previous (111) and (111) SISFs disappear with dislocation reactions, and new SISFs are formed on the $(11 \overline{1})$ and $(1 \overline{1} 1)$ planes. An extended dislocation is formed due to the dissociation of $1 / 2[1 \overline{1} 0]$ Perfect dislocation into $1 / 6[1 \overline{2} \overline{1}]$ and $1 / 6[2 \overline{1} 1]$ Shockley dislocations connected by an SISF on the (11) $)$ plane. 
Furthermore, an extrinsic stacking fault (SESF) appears on the $(11 \overline{1})$ plane (Figure $4 c_{0}$ ), which is caused by a layer of atoms inserting in the normal stacking sequence. As Figure $4 \mathrm{~d}$ shows, when the depth increases to $20.35 \AA$ (corresponding to D in Figure 3a), the (11) $\overline{1}$ ) SESF and the extended dislocation fade away; while fresh SISFs are formed on the (111), (1111) and (111) planes; what's more, a Stair-rod dislocation, which is immovable and stable, is generated by the dislocation reaction $1 / 6[\overline{211}]+1 / 6[121]$ $\rightarrow 1 / 6[\overline{1} 10]$.

As displayed in Figure 4e, when the depth reaches the maximum depth of $22.6 \AA$ (corresponding

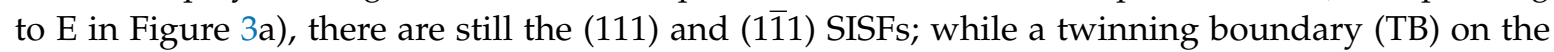
(111) plane is formed (Figure $4 \mathrm{e}_{0}$ ), and a similar behavior was observed during the nanoindentation of Ag with the (001) surface [47]. In addition, the previous Stair-rod dislocation annihilates, and a fresh $1 / 6[0 \overline{1} 1]$ Stair-rod dislocation is formed by the dislocation reaction $1 / 6[1 \overline{2} \overline{1}]+1 / 6[\overline{1} 12] \rightarrow 1 / 6[0 \overline{1} 1]$. Afterwards, with the constant rise of the indenter, dislocations will move toward the indentation and shrink, even become annihilated. In Figure 4f, as the indentation depth decreases to $14.1 \AA$ (corresponding to F in Figure 3a), there is no dislocation in the sample, while ten vacancies and four interstitials are formed due to dislocation reactions. As Figure $4 \mathrm{~g}$ shows, the indenter returns to the original position (corresponding to G in Figure 3a), vacancies and interstitials are still in the sample, but the number of interstitials decreases because of deformation recovery.
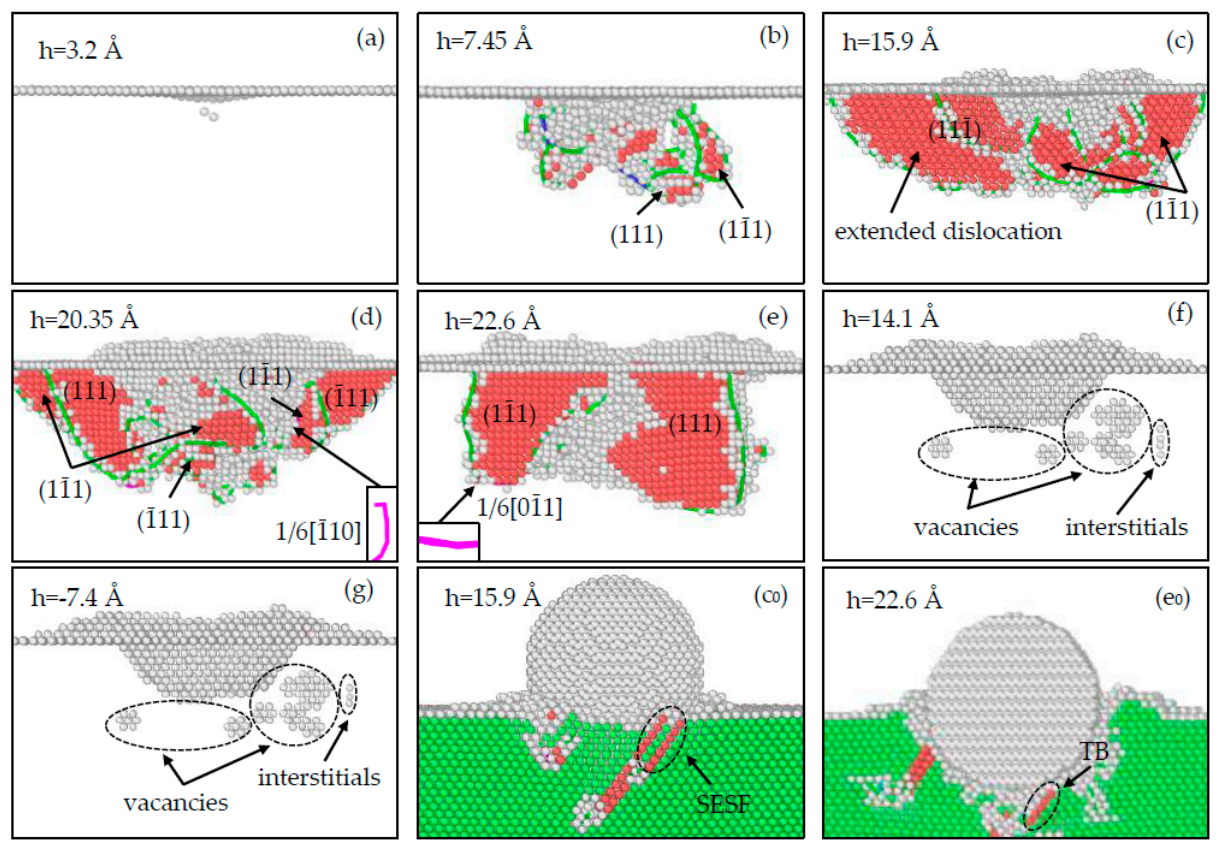

Figure 4. Defect evolution in the (100) sample during the loading process $\left(\mathbf{a}-\mathbf{g}, \mathbf{c}_{\mathbf{0}}, \mathbf{e}_{\mathbf{0}}\right)$, and the unloading process $(\mathbf{f}-\mathbf{g})$. (SESF is the external stacking fault, TB is the twinning boundary).

\subsubsection{Analysis of Defect Evolution for the (110) Sample}

As is depicted in Figure 5a, when the indentation depth reaches $3.4 \AA$ (corresponding to A in Figure 3b), a dislocation embryo nucleates and will develop into a 1/6[112] Shockley dislocation; meanwhile, the sample deforms plastically. In Figure $5 b$, as the depth increases to $6.55 \AA$ (corresponding to $B$ in Figure 3b), 1/6[112] and 1/6[211] Shockley dislocations are formed under indentation. As Figure 5c shows, when the depth reaches $10.95 \AA$ (corresponding to $C$ in Figure $3 b$ ), dislocations

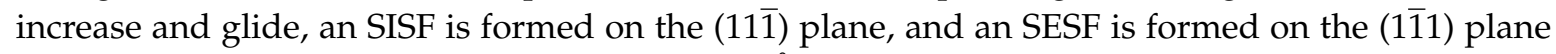
(Figure $5 c_{0}$ ). In Figure $5 d$, when the depth is $14.5 \AA$ (corresponding to D in Figure $3 b$ ), the (11̄1) SESF annihilates and a TB appears on the (111) plane, which may reduce the energies of planar defects (Figure $\left.5 \mathrm{~d}_{0}\right)$; meanwhile, there are two SISFs on the $(\overline{1} 11)$ and $(1 \overline{1} 1)$ planes. Furthermore, a $1 / 6[\overline{1} 01]$ Stair-rod dislocation is formed by the dislocation reaction $1 / 6[1 \overline{1} 2]+1 / 6[\overline{2} 1 \overline{1}] \rightarrow 1 / 6[\overline{1} 01]$. 
In Figure 5e, as the depth is $17.15 \AA$ (corresponding to E in Figure $3 b$ ), stacking faults shrink, an ESF (Figure $5 \mathrm{e}_{0}$ ) on the (111) plane is formed and the previous (1111) TB fades away because of the complex dislocation reactions. As displayed in Figure 5f, when the indentation depth reaches $20.85 \AA$ (corresponding to $\mathrm{F}$ in Figure 3b), dislocations interact with each other to form a prismatic dislocation loop, which also appeared in the nanoindentation of the $\mathrm{Ni}(011)$ surface [42]. An immovable 1/3[010] Hirth dislocation is formed by the dislocation reaction $1 / 6[\overline{112}]+1 / 6[1 \overline{1} 2] \rightarrow 1 / 3[0 \overline{1} 0]$; the (111) SESF fades away accompanying by the formation of an SISF on the (111) plane, and a fresh twin boundary is produced on the $(1 \overline{1} 1)$ plane (Figure $5 \mathrm{f}_{0}$ ).

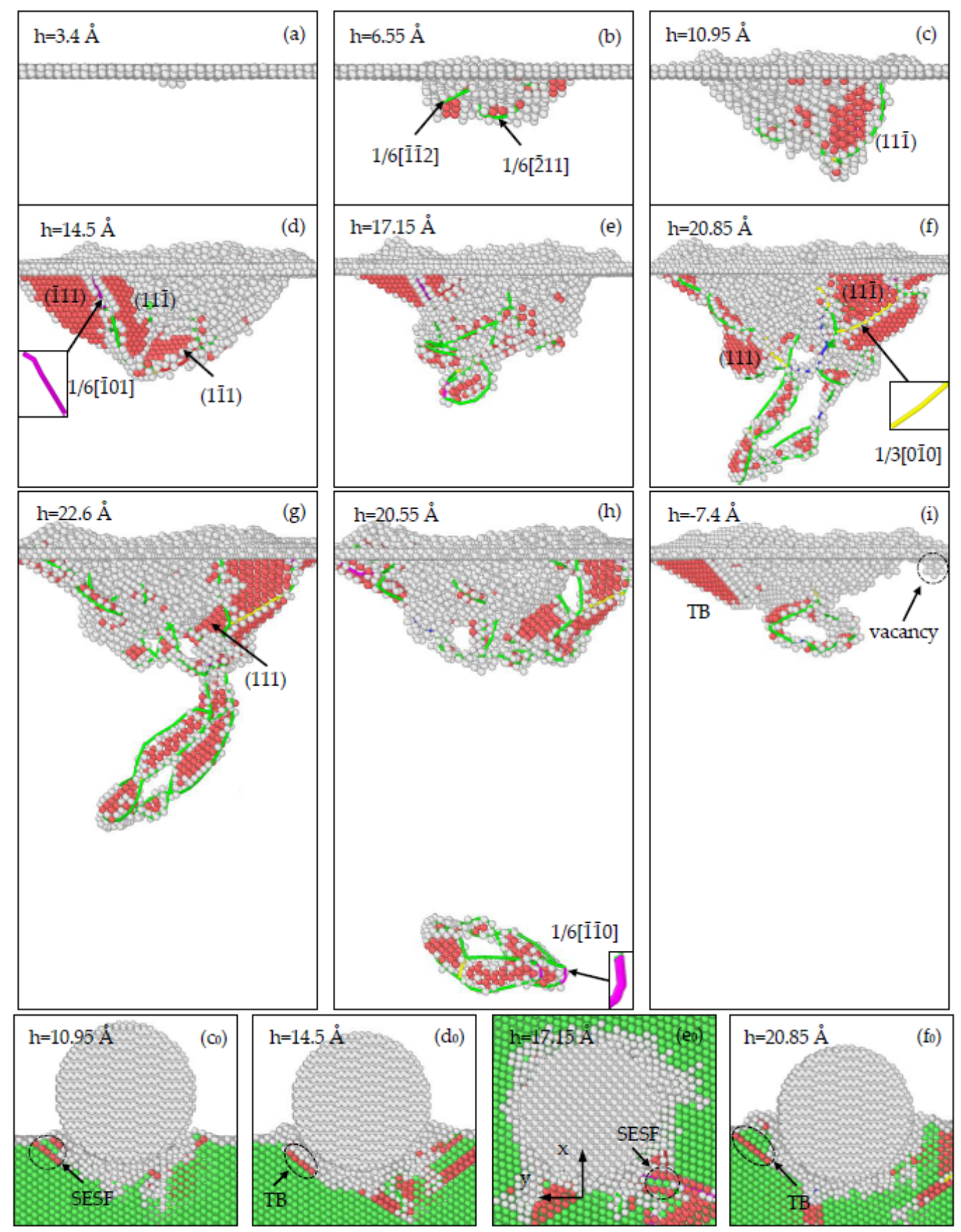

Figure 5. Defect evolution in the (110) sample during the loading process $\left(\mathbf{a}-\mathbf{g}, \mathbf{c}_{\mathbf{0}}-\mathbf{f}_{\mathbf{0}}\right)$, and the unloading process $(\mathbf{h}-\mathbf{i})$. (SESF is the external stacking fault, TB is the twinning boundary). 
As shown in Figure $5 \mathrm{~g}$, when the indentation depth increases to the maximum $22.6 \AA$ (corresponding to G in Figure 3b), the previous (111) SISF annihilates and a fresh SISF appears on the (111) plane. Moreover, the prismatic dislocation loop develops and its components react subsequently, and a $1 / 6[\overline{11} 0]$ Stair-rod dislocation is formed by the dislocation reaction $1 / 6[\overline{2} 11]+$ $1 / 6[1 \overline{21}] \rightarrow 1 / 6[\overline{110} 0]$; the growth of the prismatic dislocation loop can result in the release of energy. Afterwards, the indenter begins to rise. As Figure $5 \mathrm{~h}$ shows, when the depth decreases to $20.55 \AA$ (corresponding to $\mathrm{H}$ in Figure $3 \mathrm{~b}$ ), the prismatic dislocation loop glides toward the lower surface of the substrate along the (111) plane, which may lead to the load relaxation. As the indenter continues to rise, the prismatic dislocation loop begins to move toward the upper free surface because of the free boundary condition; meanwhile, the (11̄1) TB extends downward. In Figure $5 i$, as the indenter returns to its initial position (corresponding to I in Figure 3b), the prismatic dislocation loop returns to the bottom of the indentation and shrinks, while the (1111) TB still exists. Moreover, four vacancies are generated as the results of the dislocation reactions, which can contribute to the reduction of stress; a similar behavior was observed during the nanoindentation of the $\mathrm{FeNi}_{3}$ (110) surface, which was considered to be the result of pile-up behavior [30].

\subsubsection{Analysis of Defect Evolution for the (111) Sample}

As displayed in Figure 6a, as the indentation depth increases to $3.8 \AA$ (corresponding to A in Figure 3c), a dislocation embryo nucleates under the top surface, which will develop into a 1/6[112] Shockley dislocation. As the indentation depth increases, dislocations are formed constantly. In Figure $6 b$, when the indentation depth reaches $6.6 \AA$ (corresponding to B in Figure $3 c$ ), SISFs are

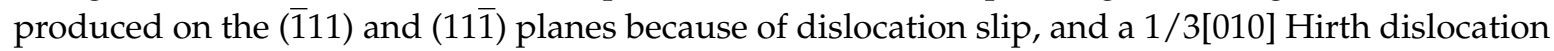
is produced by the dislocation reaction $1 / 6[211]+1 / 6[\overline{2} 1 \overline{1}] \rightarrow 1 / 3[010]$. As Figure $6 \mathrm{c}$ shows, when the depth is $10.15 \AA$ (corresponding to $C$ in Figure 3c), dislocations continue to increase, an extended dislocation is formed by a 1/2[110] Perfect dislocation dissociating into 1/6[121] and 1/6[21̄] Shockley dislocations that connected by an SISF on the (1111) plane. Furthermore, the (111) SISF fades away accompanying with the formation of the $(11 \overline{1}) \mathrm{TB}$ (Figure $6 \mathrm{c}_{0}$ ).

In Figure $6 \mathrm{~d}$, as the indentation depth increases to $16.95 \AA$ (corresponding to D in Figure 3c),

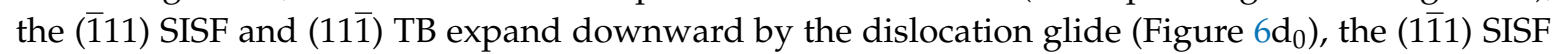
disappears accompanying with the generation of the (1111) TB and (1111) SESF (Figure $6 \mathrm{~d}_{1}$ ). What's more, a prismatic dislocation loop is formed, which was also observed in the nanoindentation of the $\mathrm{Al}$ (111) surface [48], while a $1 / 6[01 \overline{1}]$ Stair-rod dislocation is formed by the dislocation reaction $1 / 6[\overline{1} 21]$ $+1 / 6[1 \overline{1} \overline{2}] \rightarrow 1 / 6[01 \overline{1}]$ in this study. In Figure 6e, as the depth increases to $20.4 \AA$ (corresponding to $\mathrm{E}$ in Figure 3c), due to the various dislocation activities, the (111) TB and (1111) SESF annihilate, and the (1111) SISF expands downward. In addition, the prismatic dislocation loop glides toward the lower surface, and similar behavior was observed during the nanoindentation of the $\mathrm{Ni}$ (111) surface [42].

In Figure $6 f$, as the depth is the maximum $22.6 \AA$ (corresponding to F in Figure 3c), a (111) TB (Figure $6 \mathrm{f}_{0}$ ), two SISF on the ( $(\overline{1} 11)$ and $(11 \overline{1})$ plane are formed; the prismatic dislocation loop continues to glide and dissociate into two parts adhering to the side surfaces since the periodic boundary condition. However, during the nanoindentation of the $\mathrm{Al}$ (111), the prismatic dislocation loop glided downward to the bottom surface and disappeared to leave a step [48]. As Figure $6 \mathrm{~g}$ shows, when the depth is $18.15 \AA$ (corresponding to G in Figure 3c), the (111) TB and SISFs all annihilate, and the two parts that adhered to the side surfaces move to the top surface with a certain distance because of the free boundary condition. In addition, a stacking fault tetrahedron (SFT) is formed under the indentation, which was observed in the nanoindentation of the $\mathrm{FeNi}_{3}$ (111) surface [30]; and five vacancies are formed by the dislocation reactions. In Figure $6 h$, as the indenter returns to its initial position (corresponding to $\mathrm{H}$ in Figure 3c), the SFT and other dislocations annihilate with dislocation slip; while the vacancies increase to seven, and SISFs on the (111) and (111) planes are formed. 


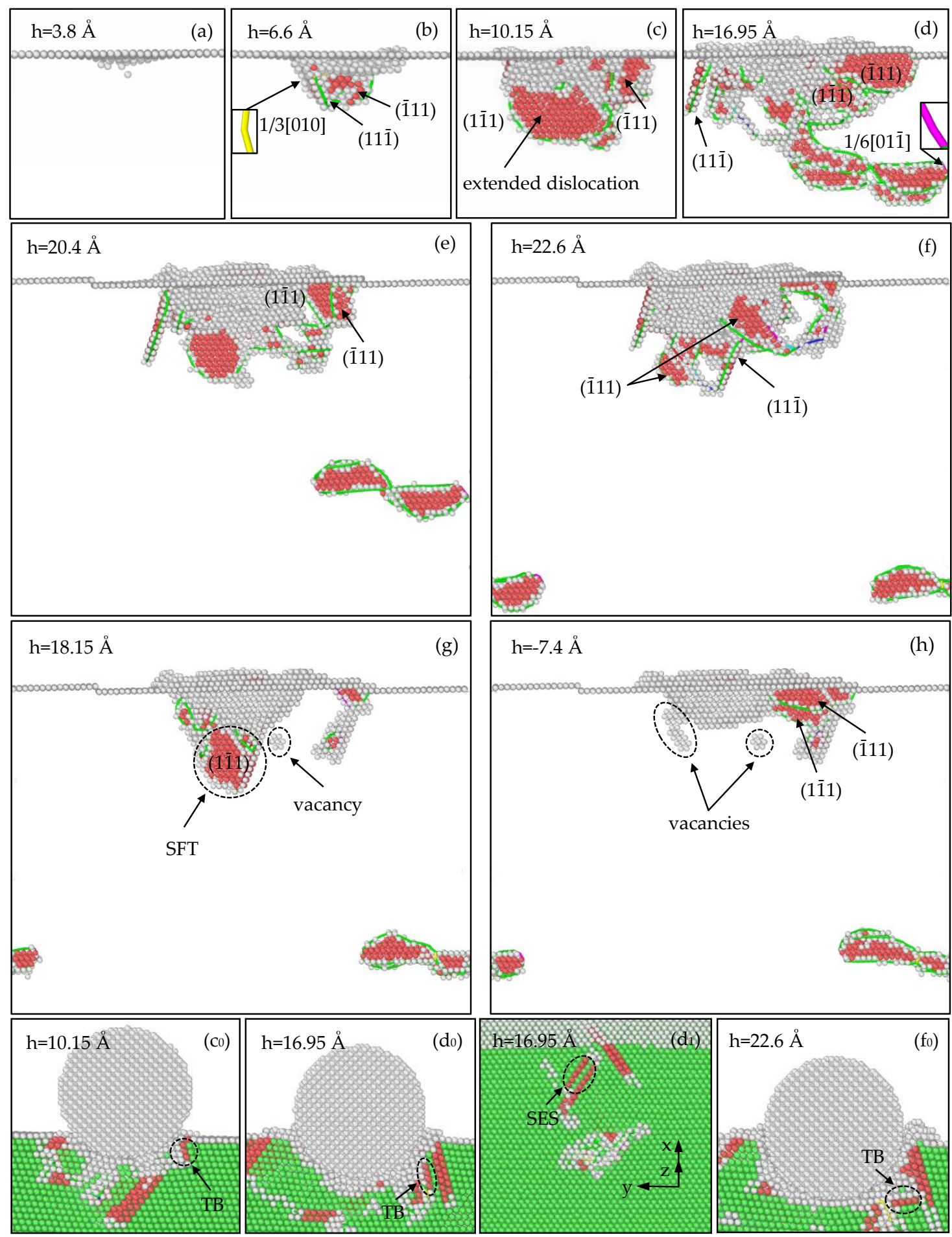

Figure 6. Defect evolution in the (111) sample during the loading process $\left(\mathbf{a}-\mathbf{f}, \mathbf{c}_{\mathbf{0}}-\mathbf{f}_{\mathbf{0}}, \mathbf{d}_{\mathbf{1}}\right)$, and the unloading process $(\mathbf{g}-\mathbf{h})$. (SFT is the stacking fault tetrahedron.).

\subsection{Analysis of Strain Energy for Different Samples}

As is depicted in Figure 7, for each sample, with the increase of step, the strain energy increases to the maximum due to the intensification of plastic deformation; meanwhile, the indentation depth also reaches the maximum. Afterwards, the energy decreases with depth owing to the deformation recovery. It can be seen that the crystal orientation has a significant effect on strain energy. In the 
plastic deformation stage, the strain energy of the (111) sample is the highest, followed by the (110) sample, while the strain energy of the (100) sample is the lowest. These differences are related to the difficulty of activating slip system in different samples. For the (111) sample, the slip system is activated difficultly, the lattice distortion degree is great, hence the strain energy of the system is the highest. For the (100) sample, the slip system is activated easily, the lattice distortion degree is small, hence the strain energy of the system is the lowest.

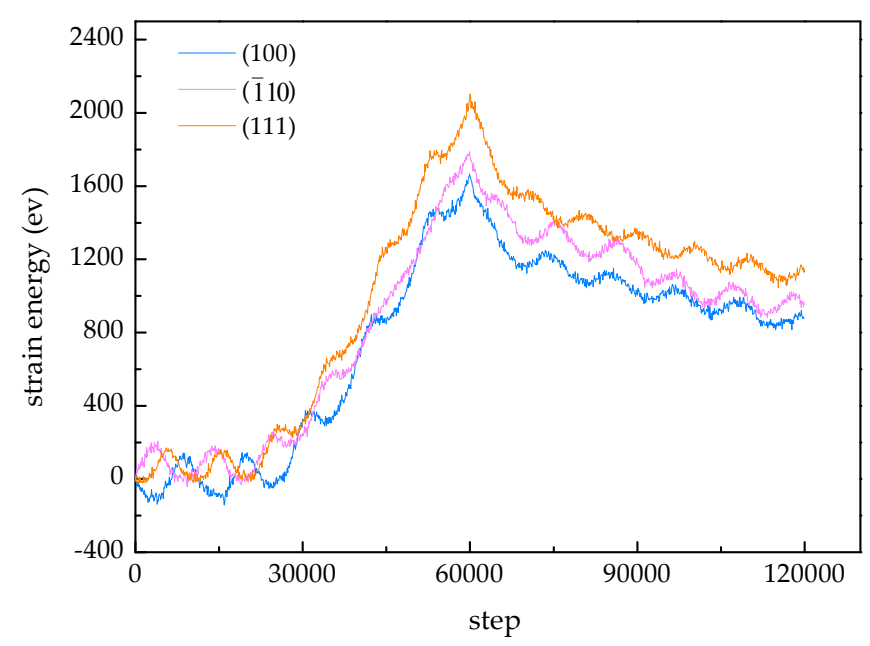

Figure 7. Strain energy-step curves of different samples.

\subsection{Calculation of Hardness and Elastic Modulus}

In order to further investigate the effect of the crystal orientation on $\gamma$-TiAl during nanoindentation, the Oliver-Pharr method [49,50] is employed to calculate the elastic modulus and hardness. The hardness is the resistance of materials to plastic deformation, it can be calculated by Equations (2)-(6):

$$
\begin{gathered}
H=\frac{P_{\max }}{A_{c}} \\
A_{c}=\pi a^{2}=\pi\left(2 R h_{c}-h_{c}{ }^{2}\right) \\
h_{c}=h_{\max }-\varepsilon \frac{P_{\max }}{S} \\
S=\left.\frac{d p}{d h}\right|_{h=h_{\max }} \\
P=B\left(h-h_{f}\right)^{m}
\end{gathered}
$$

where, $P_{\max }$ is the load at the maximum depth, $A_{c}$ is the contact area, $R$ is the indenter radius, $h_{c}$ is the contact depth, $h_{\max }$ is the maximum depth, $\varepsilon$ is the correction factor, and $\varepsilon=0.75$ for the spherical indenter [51], fitting 25-50\% of the incipient unloading curve with Equation (6) and the stiffness $S$ is obtained by Equation (5), $h_{f}$ is the indentation depth after unloading, $\mathrm{B}$ and $\mathrm{m}$ are fitting parameters.

The value of hardness for each sample is listed in Table 2. Obviously, the value of the (111) sample is the maximum, and that of the (100) sample is the minimum. The results indicate that the (100) sample has the weakest resistance to plastic deformation, as the nanoindentation along the [100] orientation is the most beneficial to activating the slip system; however, for the (111) sample, the nanoindentation along the [111] orientation is the most unfavorable for activating the slip system, and the substrate has the strongest resistance to plastic deformation. Note that the hardness of the (110) sample is in good agreement with the experimental results $6.8 \pm 0.8 \mathrm{GPa}$ [31]. 
Table 2. Values of hardness and elastic modulus for different samples.

\begin{tabular}{cccc}
\hline Samples & $\mathbf{( 1 0 0 )}$ & $\mathbf{( 1 1 0 )}$ & $\mathbf{( 1 1 1 )}$ \\
\hline Hardness (GPa) & 6.42 & 6.63 & 6.91 \\
Elastic modulus (GPa) & 164.5 & 175.8 & 192.4 \\
\hline
\end{tabular}

From a macro point of view, the elastic modulus represents the ability of a material to resist elastic deformation. At the micro level, the elastic modulus is a reflection of the bond strength between atoms, ions or molecules. The elastic modulus can be calculated by the reduced elastic modulus $E_{r}$, which takes into account the combined elastic effects of the indenter and substrate as in Equation (7):

$$
E_{r}=\frac{S \sqrt{\pi}}{2 \beta \sqrt{A_{c}}}
$$

where $\beta$ is a constant related to the geometrical shape of the indenter, and $\beta=1$ for the spherical indenter.

The finally elastic modulus is calculated from Equation (8):

$$
\frac{1}{E_{r}}=\frac{1-v^{2}}{E}+\frac{1-v_{i}^{2}}{E_{i}}
$$

where $E$ and $E_{i}$ are the elastic modulus of the substrate and indenter, respectively; $v$ and $v_{i}$ are the Poisson's ratios of the substrate and indenter, respectively. Due to the indenter is rigid, its elastic modulus is infinite, and its Poisson's ratio is 0 [26], while the Poisson's ratio of the substrate is 0.23 [52].

The value of elastic modulus for each sample is listed in Table 2. Clearly, the value of the (100) sample is the minimum, which suggests that the elastic deformation of this case is the most intense; the value of the (111) sample is the maximum, and its elastic deformation is the slightest. The previous experimental results indicated that the elastic modulus of the (110) sample is higher than that of the (100) sample [31], which is similar to our results. The main reason for these differences is that the bond strength of atoms in the (100) sample is the weakest and the cohesive energy is the lowest; on the contrary, the bond strength of atoms in the (111) sample is the strongest, and the cohesive energy is the highest. Moreover, the value of the (100) sample is within the range of 157.2-167.9 GPa obtained in other works [26,53], and the value of the (110) sample is consistent with the experimental results $163 \pm 8 \mathrm{GPa}[31]$.

\section{Conclusions}

In this paper, the effect of crystal orientation on the deformation mechanisms and mechanical properties of $\gamma$-TiAl during nanoindentation at $300 \mathrm{~K}$ was demonstrated by molecular dynamics simulations. The load-depth curve, the defect evolution process as well as the related mechanical parameters of different samples were analyzed. In particular, the following conclusions can be drawn:

(1) During the loading process of each case, there is no pronounced pop-in event in the load-depth curve when the initial plastic deformation of $\gamma$-TiAl occurs, which can be explained by the dislocation nucleating before the first load drop.

(2) During the unloading process of the (110) and (111) cases, there is a peak in both load-depth curves, because several dislocations move to the free surface and annihilate causing the release of energy.

(3) Stacking faults (intrinsic stacking faults and extrinsic stacking faults), twin boundaries and vacancies are generated in all cases. While interstitials are formed only in the (100) sample; a stacking fault tetrahedron is formed in the (111) sample; and a prismatic dislocation loop is formed in both the (110) and (111) samples. 
(4) For the (110) sample, the prismatic dislocation loop moves to the upper free surface and shrinks with the rise of the indenter. However, for the (111) sample, the prismatic dislocation loop continues to glide downward with the indenter returning and finally dissociates into two parts adhering on the side surfaces of the substrate, which is caused by the periodic boundary condition.

(5) The values of the critical load, strain energy, elastic modulus and hardness for the (111) sample are the maximal, and those for the (100) sample are the minimal. These differences are attributed to the bond strength of atoms and the ease of crystal slip in different samples. Besides, the orientation dependence of the elastic modulus is greater than the hardness and critical load.

Author Contributions: Conceptualization, X.F., Z.R., and C.Y.; Methodology, H.C., X.F.; Software, R.F. (Rong Fu), H.C.; Investigation, X.F.; Resources, Z.R., R.F. (Ruicheng Feng); Data Curation, R.F. (Rong Fu); Writing-Original Draft Preparation, X.F.; Visualization, C.Y., R.F. (Rong Fu); Supervision, Z.R.; Project Administration, R.F. (Ruicheng Feng).

Funding: This research was funded by [the National Natural Science Foundation of China] grant number [51865027]; [the National Natural Science Foundation of China] grant number [07020086]; and [the Program for Changjiang Scholars and Innovative Research Team in University of Ministry of Education of China] grant number [IRT_15R30].

Acknowledgments: This research was supported by the Gansu computing centre.

Conflicts of Interest: The authors declare no conflict of interest.

\section{References}

1. Clemens, H.; Mayer, S. Advanced Intermetallic TiAl Alloys. Mater. Sci. Forum 2016, 879, 113-118. [CrossRef]

2. Clemens, H.; Mayer, S. Design, Processing, Microstructure, Properties, and Applications of Advanced Intermetallic TiAl Alloys. Adv. Eng. Mater. 2013, 15, 191-215. [CrossRef]

3. Clemens, H.; Mayer, S. Intermetallic titanium aluminides in aerospace applications-processing, microstructure and properties. Mater. High Temp. 2016, 33, 560-570. [CrossRef]

4. Tezok, F.; Brahimi, M.; Paraschivoiu, I. Investigation of the physical processes underlying the ice accretion phenomena. In Proceedings of the Aiaa Aerospace Sciences Meeting \& Exhibit, Grapevine, TX, USA, 7-10 January 2013.

5. Stegall, D.E.; Elmustafa, A.A. Activation volume of pure face centered cubic metals using uniaxial testing and nanoindentation equipped with high load capability. Mater. Res. Express 2016, 3, 105024. [CrossRef]

6. Bigl, S.; SchoBerl, T.; Wurster, S.; Cordill, M.J.; Kiener, D. Correlative Microstructure and Topography Informed Nanoindentation of Copper Films. Surf. Coat. Technol. 2016, 308, 404-413. [CrossRef]

7. Wang, Y.; Cheng, G.; Tay, S.L.; Guo, Y.; Sun, X.; Gao, W. Effects of Bi Addition on the Microstructure and Mechanical Properties of Nanocrystalline Ag Coatings. Materials 2017, 10, 932. [CrossRef] [PubMed]

8. Ding, Y.; Chromik, R.R. Relationship between indentation plastic zone size and residual stresses in plastically deformed Fe. Mater. Sci. Eng. A 2017, 696, 1-9. [CrossRef]

9. Huape, E.; Villafañe, A.M.; Soto, R.P.T.; Macias, A.H. Mechanical properties of $\gamma$-TiAl alloys on the Aluminium-Rich side by Nanoindentation. Int. J. Sci. Adv. Tech. 2015, 5, 1-6.

10. Guitton, A.; Kriaa, H.; Bouzy, E.; Guyon, J.; Maloufi, N. A Dislocation-Scale Characterization of the Evolution of Deformation Microstructures around Nanoindentation Imprints in a TiAl Alloy. Materials 2018, 11, 305. [CrossRef] [PubMed]

11. Han, J.K.; Li, X.; Dippenaar, R.; Liss, K.D.; Kawasaki, M. Microscopic plastic response in a bulk nano-structured TiAl intermetallic compound processed by high-pressure torsion. Mater. Sci. Eng. A 2018, 714, 84-92. [CrossRef]

12. Khosravani, A.; Morsdorf, L.; Tasan, C.C.; Kalidindi, S.R. Multiresolution mechanical characterization of hierarchical materials: Spherical nanoindentation on martensitic Fe-Ni-C steels. Acta Mater. 2018, 153, 257-269. [CrossRef]

13. Li, R.; Mo, C.; Liao, Y. Mechanical Properties of U-Cu Intermetallic Compound Measured by Nanoindentation. Materials 2018, 11, 2215. [CrossRef] [PubMed]

14. Heng, C.; Taihua, Z.; Yi, M. Effect of Applied Stress on the Mechanical Properties of a Zr-Cu-Ag-Al Bulk Metallic Glass with Two Different Structure States. Materials 2017, 10, 711. [CrossRef] 
15. Ying, S.; Ma, L.; Sui, T.; Papadaki, C.; Salvati, E.; Romano Brandt, L.; Zhang, H.; Korsunsky, A.M. Nanoscale Origins of the Size Effect in the Compression Response of Single Crystal Ni-Base Superalloy Micro-Pillars. Materials 2018, 11, 561. [CrossRef] [PubMed]

16. Xiong, K.; Liu, X.; Gu, J. Multiscale modeling of lattice dynamical instability in gamma-TiAl crystal. Model. Simul. Mater. Sci. Eng. 2015, 23, 045006. [CrossRef]

17. Stukowski, A.; Albe, K.; Farkas, D. Nanotwinned fcc metals: Strengthening versus softening mechanisms. Phys. Rev. B 2010, 82, 4196-4205. [CrossRef]

18. Brostow, W.; Hagg Lobland, H.E. Materials: Introduction and Applications; John Wiley \& Sons: New York, NY, USA, 2017; Chapter 15; p. 184.

19. Liu, Q.; Deng, L.; Wang, X.; Li, J. Formation of stacking fault tetrahedron in single-crystal Cu during nanoindentation investigated by molecular dynamics. Comput. Mater. Sci. 2017, 131, 44-47. [CrossRef]

20. Jiao, S.; Tu, W.; Zhang, P.; Zhang, W.; Qin, L.; Sun, Z.; Chen, J. Atomistic insights into the prismatic dislocation loop on $\mathrm{Al}$ (100) during nanoindentation investigated by molecular dynamics. Comput. Mater. Sci. 2018, 143, 384-390. [CrossRef]

21. Shih-Wei, L.; Ren-Zheng, Q.; Te-Hua, F. Molecular dynamics simulations of nanoindentation and scratch in $\mathrm{Cu}$ grain boundaries. Beilstein J. Nanotechnol. 2017, 8, 2283-2295. [CrossRef]

22. Talaei, M.S.; Nouri, N.; Ziaei-Rad, S. Grain Boundary Effects on Nanoindentation of Fe Bicrystal Using Molecular Dynamic. Mech. Mater. 2016, 102, 97-107. [CrossRef]

23. Abu-Shams, M.; Shabib, I. Effect of voids on nanoindentation response of Fe- $10 \% \mathrm{Cr}$ alloys using molecular dynamics simulation. Mater. Express 2017, 7, 329-340. [CrossRef]

24. Biao, Y.; Bailin, Z.; Xingjian, H.; Pengfei, H.; Zhufeng, Y. Effect of Void on Nanoindentation Process of Ni-Based Single Crystal Alloy. Acta Metall. Sin. 2016. [CrossRef]

25. Dasilva, C.J.; Rino, J.P. Atomistic simulation of the deformation mechanism during nanoindentation of gamma titanium aluminide. Comput. Mater. Sci. 2012, 62, 1-5. [CrossRef]

26. Xu, S.; Wan, Q.; Sha, Z.; Liu, Z. Molecular dynamics simulations of nanoindentation and wear of the $\gamma$-TiAl alloy. Comput. Mater. Sci. 2015, 110, 247-253. [CrossRef]

27. Jun, T.S.; Armstrong, D.E.J.; Britton, T.B. A nanoindentation investigation of local strain rate sensitivity in dual-phase Ti alloys. J. Alloys Compd. 2016, 672, 282-291. [CrossRef]

28. Ziegenhain, G.; Urbassek, H.M.; Hartmaier, A. Influence of crystal anisotropy on elastic deformation and onset of plasticity in nanoindentation: A simulational study. J. Appl. Phys. 2010, 107, 156. [CrossRef]

29. Xiong, K.; Lu, H.; Gu, J. Atomistic simulations of the nanoindentation-induced incipient plasticity in $\mathrm{Ni}_{3} \mathrm{Al}$ crystal. Comput. Mater. Sci. 2016, 115, 214-226. [CrossRef]

30. Xiong, $\mathrm{K} . ; \mathrm{Gu}$, J. Understanding pop-in phenomena in $\mathrm{FeNi}_{3}$ nanoindentation. Intermetallics 2015, 67, 111-120. [CrossRef]

31. Kempf, M.; Goken, M.; Vehoff, H. The mechanical properties of different lamellae and domains in PST-TiAl investigated with nanoindentations and atomic force microscopy. Mater. Sci. Eng. A 2002, 329-331, 184-189. [CrossRef]

32. Zambaldi, C.; Raabe, D.; Roters, F. Plastic anisotropy of $\gamma$-TiAl revealed by axisymmetric indentation. Acta Mater. 2010, 58, 3516-3530. [CrossRef]

33. Demidov, A.G.; Fortunato, M.E.; Colina, C.M. Update 0.2 to "pysimm: A python package for simulation of molecular systems". Softwarex 2018, 7, 70-73. [CrossRef]

34. Zope, R.R.; Mishin, Y. Interatomic potentials for atomistic simulations of the TiAl system. Phys. Rev. B 2003, 68, 366-369. [CrossRef]

35. Blonski, S.; Brostow, W.; Kubát, J. Molecular-Dynamics Simulations of Stress Relaxation in Metals and Polymers. Phys. Rev. B 1994, 49, 6494. [CrossRef]

36. Baowan, D.; Triampo, W.; Triampo, D. Encapsulation of $\mathrm{TiO}_{2}$ nanoparticles into single-walled carbon nanotubes. New J. Phys. 2009, 11, 093011. [CrossRef]

37. Peng, P.; Liao, G.; Shi, T.; Tang, Z.; Gao, Y. Molecular dynamic simulations of nanoindentation in aluminum thin film on silicon substrate. Appl. Surf. Sci. 2010, 256, 6284-6290. [CrossRef]

38. Jian, S.R.; Fang, T.H.; Chuu, D.S. Nanomechanical characterizations of InGaN thin films. Appl. Surf. Sci. 2006, 252, 3033-3042. [CrossRef]

39. Liang, H.; Woo, C.H.; Huang, H.; Ngan, A.H.W.; Yu, T.X. Crystalline plasticity on copper (001), (110), and (111) surfaces during nanoindentation. Comp. Model. Eng. 2004, 6, 105-114. [CrossRef] 
40. Zhu, P.Z.; Hu, Y.Z.; Wang, H. Atomistic simulations of the effect of a void on nanoindentation response of nickel. Sci. China Ser. G 2010, 53, 1716-1719. [CrossRef]

41. Fu, T.; Peng, X.; Chen, X.; Weng, S.; Hu, N.; Li, Q.; Wang, Z. Molecular dynamics simulation of nanoindentation on $\mathrm{Cu} / \mathrm{Ni}$ nanotwinned multilayer films using a spherical indenter. Sci. Rep. 2016, 6, 35665. [CrossRef] [PubMed]

42. Hu, T.Y.; Zheng, B.L.; Hu, M.Y.; He, P.F.; Yue, Z.F. Molecular dynamics simulation of incipient plasticity of nickel substrates of different surface orientations during nanoindentation. Mater. Sci. Technol. 2015, 31, 325-331. [CrossRef]

43. Cross, G.L.W.; Schirmeisen, A.; Grütter, P.; Düring, U.T. Plasticity, healing and shakedown in sharp-asperity nanoindentation. Nat. Mater. 2006, 5, 370-376. [CrossRef] [PubMed]

44. Xiong, K.; Liu, X.; Li, C.; Gu, J. Phonon instability of Co single crystal in uniaxial tension and nanoindentation. Comput. Mater. Sci. 2015, 99, 47-56. [CrossRef]

45. Kelchner, L. Dislocation Nucleation and Defect Structure during Surface Indentation. Phys. Rev. B 1998, 58, 11085-11088. [CrossRef]

46. Alhafez, I.A.; Ruestes, C.J.; Gao, Y.; Urbassek, H.M. Nanoindentation of hcp metals: A comparative simulation study of the evolution of dislocation networks. Nanotechnology 2016, 27, 045706. [CrossRef] [PubMed]

47. Li, J.; Ni, Y.; Wang, H.; Mei, J. Effects of Crystalline Anisotropy and Indenter Size on Nanoindentation by Multiscale Simulation. Nanoscale Res. Lett. 2009, 5, 420-443. [CrossRef] [PubMed]

48. Lee, Y.; Park, J.Y.; Kim, S.Y.; Jun, S.; Im, S. Atomistic simulations of incipient plasticity under Al (111) nanoindentation. Mech. Mater. 2005, 37, 1035-1048. [CrossRef]

49. Oliver, W.C.; Pharr, G.M. Measurement of hardness and elastic modulus by instrumented indentation: Advances in understanding and refinements to methodology. J. Mater. Res. 2004, 19, 3-20. [CrossRef]

50. Oliver, W.C.; Pharr, G.M. An improved technique for determining hardness and elastic modulus using load and displacement sensing indentation experiments. J. Mater. Res. 1992, 7, 20. [CrossRef]

51. Belak, J.; Boercker, D.B.; Stowers, I.F. Simulation of nanometer-scale deformation of metallic and ceramic surfaces. MRS Bull. 1993, 18, 55-60. [CrossRef]

52. He, Y.; Schwarz, R.B.; Migliori, A.; Whang, S.H. Elastic constants of single crystal $\gamma$-TiAl. J. Mater. Res. 1995, 10, 1187-1195. [CrossRef]

53. Fu, H.; Li, D.; Peng, F.; Gao, T.; Cheng, X. Structural and elastic properties of $\gamma$-TiAl under high pressure from electronic structure calculations. J. Alloys Compd. 2009, 473, 255-261. [CrossRef] 